\title{
Perspective
}

\section{Do Preclinical Findings of Methamphetamine-Induced Motor Abnormalities Translate to an Observable Clinical Phenotype?}

\author{
Michael P Caligiuri*,' and Casey Buitenhuys' \\ 'UCSD School of Medicine and Department of Psychiatry and Psychiatry Service, VA San Diego Healthcare System, La Jolla, CA, USA
}

\begin{abstract}
This review summarizes the preclinical literature of the effects of methamphetamine (MA) on subcortical dopaminergic and GABAergic mechanisms underlying motor behavior with the goal of elucidating the clinical presentation of human MA-induced movement disorders. Acute and chronic MA exposure in laboratory animal can lead to a variety of motor dysfunctions including increased locomotor activity, stereotypies, diminished or enhanced response times, and parkinsonian-like features. With the exception of psychomotor impairment and hyperkinesia, MA-induced movement disorders are not well documented in humans. This review attempts to draw parallels between the animal and human changes in basal ganglia neurochemistry associated with MA exposure and offers explanations for why a parkinsonian phenotype is not apparent among individuals who use and abuse MA. Significant differences in the expression of neurotoxicity and presence of multiple environmental and pharmacologic confounds may account for the lack of a parkinsonian phenotype in humans despite evidence of altered dopamine function.
\end{abstract}

Neuropsychopharmacology (2005) 30, 2 I25-2134. doi:10.1038/sj.npp. I300859; published online 10 August 2005

Keywords: methamphetamine; basal ganglia; dopamine; parkinsonism; hyperkinetic movement disorders

\section{INTRODUCTION AND OVERVIEW}

The goal of this review paper is to summarize the preclinical and clinical evidence for subcortical mechanisms underlying the motor abnormalities associated with methamphetamine (MA) abuse. The focus of this review will be on basal ganglia mechanisms because of the powerful neurochemical interactions that occur between MA and dopamine (Ricaurte et al, 1980, 1984; O'Dell et al, 1993; Volkow et al, 1999), GABA (Bustamante et al, 2002; Kamata and Kameyama, 1986), and glutamate (GLU) (Sonsalla et al, 1989; Nash and Yamamoto, 1992; Abekawa et al, 1994), three important neurotransmitters present throughout the basal ganglia. Recent findings indicate that the motor consequences of even brief exposures to psychostimulants can persist long after the stimulant is discontinued (Balogh et al, 2004). The state of knowledge is quite advanced with regard to the effects of MA exposure on brain neurochemistry. However, our understanding of how these changes impact motor behavior in the living animal is less sophisticated particularly with regard to MA-induced motor dysfunction in humans. In this paper, we review selected

\footnotetext{
*Correspondence: Dr MP Caligiuri, Department of Psychiatry (0603), University of California, San Diego, 9500 Gilman Drive, La Jolla, CA 92093, USA, Tel: + I 858642 1266, Fax: + I 858642 |447, E-mail: mcaligiuri@ucsd.edu

Received 21 December 2004; revised 18 May 2005; accepted 29 June 2005

Online publication: 6 July 2005 at http://www.acnp.org/citations/ Npp070605040604/default.pdf
}

research on the anatomic and neurochemical bases for MA-induced motor abnormalities in laboratory animals. We then discuss whether these mechanisms are sufficient to produce movement disorders in humans who abuse MA and cite similarities and differences between MA-induced motor abnormalities in laboratory animals and humans. Limitations in the clinical literature are discussed and recommendations for further research are presented.

\section{NEUROANATOMY AND CHEMISTRY OF THE SUBCORTICAL MOTOR SYSTEM}

Progress has been made in identifying the underlying neural circuitry involved in extrapyramidal motor function in humans and primates. Over the past 20 years, the brain systems involved in extrapyramidal motor function have been elucidated to an important degree. The regions involved form a circuit, through which information is passed from the cortex, to the striatum, then to the globus pallidus, to the thalamus, and back to the cortex (Albin et al, 1989; Alexander et al, 1990; Delong, 1990). The cortico-striato-pallido-thalamic (CSPT) circuits are the best known and most thoroughly investigated groups of circuits in the brain (Lichter and Cummings, 2001; Bradshaw, 2001). Figure 1 shows a diagram of the CSPT motor circuit. The CSPT motor circuit consists of direct and indirect motor loops involving the basal ganglia. The direct loop consists of a circuit involving the cortex, striatum, internal segment of the globus pallidus/substantia nigra pars reticulata 


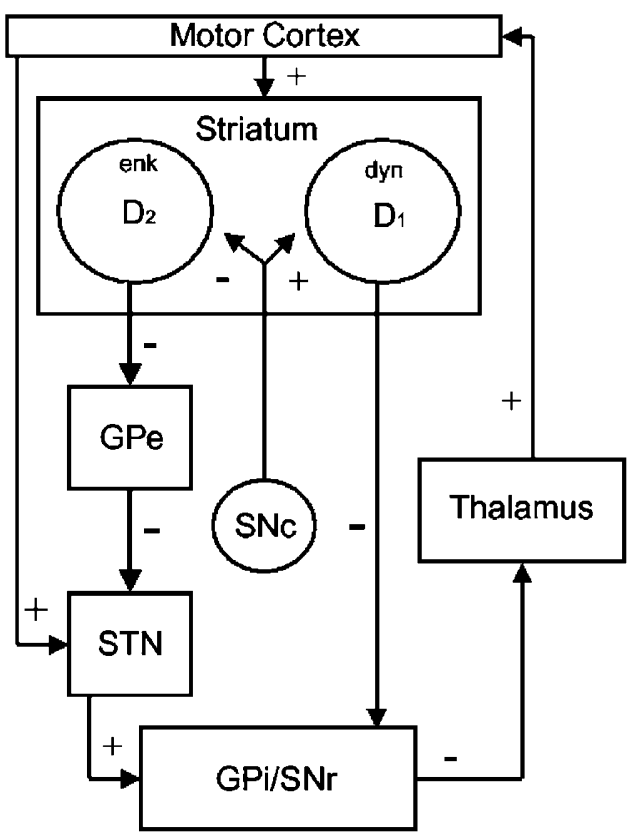

Figure I Diagram of the cortico-striato-pallido-thalamic motor circuit showing inhibitory $(-)$ and excitatory $(+)$ pathways. Abbeviations: DI — dopamine DI receptor; D2 — dopamine D2 receptor; dyn-dynorphin; enk-enkephalin; GPe-external segment of the globus pallidus; $\mathrm{GPi}$-internal segment of the globus pallidus; $\mathrm{SNc}$ - substantia nigra pars compacta; SNr-substantia nigra pars reticulata; STN — subthalamic nucleus.

(GPi/SNr) complex, thalamus and cortex, in which dopamine input from the substantia nigra pars compacta $(\mathrm{SNc})$ is excitatory upon GABAergic and cholinergic striatal neurons. The indirect loop consists of a more complex circuit, involving the cortex, striatum, external segment of the globus pallidus (GPe), the subthalamic nucleus (STN), $\mathrm{GPi} / \mathrm{SNr}$ complex, thalamus, and cortex, in which dopamine from the SNc is inhibitory to GABAergic neurons of the striatum.

Localizing the neuronal circuits involved in parkinsonism has been the focus of animal and human research for over two decades. Primate models of basal ganglia disorders demonstrate that parkinsonian bradykinesia results from disruptions of normal inhibitory striatal projections to the internal segment of the globus pallidus (Albin et al, 1989; Alexander et al, 1990; Delong, 1990). Excessive inhibition of outflow projections from GPi to the thalamus thus reduces the thalamocortical excitation and reduced cortical excitation. This in turn would lead to a reduction (hypokinesia) or slowing (bradykinesia) of movement. Horak and Anderson (1984) and Mink and Thatch (1993) observed that monkeys with lesions causing increased activity within the GPi exhibited significant motor slowing. The therapeutic effects of surgical disruption of the output of the GPi in Parkinson disease are also consistent with this model (Pfann et al, 1998; Alkhani and Lozano, 2001; Lozano and Lang, 2001; Dostrovsky et al, 2002).

Neuroanatomical and neurochemical bases for dyskinesia have been elucidated through studies of animal lesions (Alexander et al, 1990; Delong, 1990) and drug-induced dyskinesia in humans (Pahl et al, 1995; Rascol et al, 1998; Brooks et al, 2000; Henry et al, 2003). Dyskinesia can result from a loss of striatopallidal GABAergic inhibitory outflow to thalamic neurons causing increased thalamo-cortical excitation (Albin et al, 1989; Alexander et al, 1990; Delong, 1990). This model assumes strong interactions between dopamine (at the level of the striatum), enkephalin (mediating GABAergic activity), inhibitory GABA (within the globus pallidus), and excitatory GLU (at the level of the subthalamic nucleus).

\section{MA-INDUCED ALTERATIONS IN NEUROCHEMISTRY}

\section{Preclinical Studies}

Several mechanisms account for the alterations in striatal neurochemistry in rats following exposure to MA including postsynaptic elevation in nigrostriatal monoamine levels, increased striatal dopamine turnover, neurotoxic effects on striatal cells via both apoptotic and neurotoxic mechanisms, and reactive gliosis or an inflammation response.

MA exerts powerful effects on several neurochemical systems throughout the brain, including dopamine (Ricaurte et al, 1980, 1984; O'Dell et al, 1993), GABA (Kamata and Kameyama, 1986; Burrows and Meshul, 1999; Bustamante et al, 2002), and GLU (Sonsalla et al, 1989; Nash and Yamamoto, 1992; Abekawa et al, 1994; Burrows and Meshul, 1999). MA is a highly lipophilic monoamine that is capable of entering presynaptic vesicles and competing for resident monoamines causing excessive release postsynaptically (Kuczenski, 1983). Both acute and prolonged MA exposures can elevate nigrostriatal dopamine postsynaptically (Kita et al, 2003; Cadet et al, 2003). Acute MA exposure can increase dopamine turnover in the caudate nucleus, as measured by the ratio of DOPAC (3,4-dihyrdroxyphenylacetic acid) to HVA (homovanillic acid, both intermediate metabolites of dopamine) relative to dopamine (Pereira et al, 2002). Bustamante et al (2002) reported changes in monoamines and peptides during an acute MA binge in the basal ganglia. Using in vivo microdialysis, they found a 10 times increase in nigral dopamine and a 40 times increase in the neostriatum in rodents. Level of dynorphin B, a cotransmitter released with excitation, was doubled in the neostriatum and substantia nigra. Prolonged exposure to MA has neurotoxic effects on striatal cells via both apoptotic (Cadet et al, 2003) and neurotoxic mechanisms (Davidson et al, 2001) associated with a marked decrease in tyrosine hydroxylase activity, dopamine, and dopamine transporter (DAT) binding sites in the striatum (Kogan et al, 1976; Gibb et al, 1990). The acute neurochemical effects of MA appear to be mediated by a precipitous rise in postsynaptic dopamine, with relative activation of the direct circuit via GLU and altered cotransmitter release. Chronic administration of these sympathomimetics appears to cause a relative decrease in the neural catecholamine activity at baseline as measured by dopamine receptor and ligand populations.

Glial cell activation is an important end point marking neurotoxicity in MA-exposed animals. Chronic exposure to $\mathrm{MA}$ induces reactive gliosis in the striatum (Escubedo $e t$ al, 1998; Miller et al, 2000; Guilarte et al, 2003) as well as other brain regions including the cerebellum and hippocampus 
(Escubedo et al, 1998). Miller et al (2000) evaluated striatal levels of glial fibrillary acidic protein (GFAP) as a marker of dopamine nerve terminal degeneration in the mouse striatum. Exposure to neurotoxic dosages of MA resulted in persistent decreases in striatal dopamine and its metabolites (DOPAC and HVA) as well as a $300-400 \%$ increase in GFAP. These alterations were observed to a much lesser extent in younger (2-3 months) compared to older (12 months) animals. Work by Thomas et al (2004) and Thomas and Kuhn (2005) indicates that MA-induced microglial activation may be attenuated in animals previously treated with MA, suggesting that animals can develop tolerance to the neurotoxic and degenerative effects of MA.

Studies of abstinence have enhanced our understanding of MA influence on basal ganglia neurochemistry. Friedman et al (1998) exposed 60-day-old rats to neurotoxic levels of MA and investigated monoamine depletion in groups of animals killed 48, 139, and 237 days later. There were significant depletions in post-mortem monoamine tissue at 48 days but not 139 and 237 days in dopamine, serotonin, and their metabolites. 5-HT within the medial prefrontal cortex, caudate, and hippocampus were reduced to $30 \%$ of control with recovery in the medical prefrontal cortex and caudate to $70 \%$ of control following long-term abstinence. Additionally, caudate dopamine reduced to $30 \%$ of control levels and showed recovery to $80 \%$ following long-term abstinence. Melega et al (1997) reported decreases in presynaptic striatal dopamine of $60 \% 1-2$ weeks following MA exposure with partial recovery when measured 6 and 12 weeks after acute MA exposure. Cass and Manning (1999) utilized in vivo microdialysis studies in rats pretreated with acute MA doses and demonstrated that amphetamine and potassium-evoked outflow of dopamine in the striatum would fully recover at 12 months. These data suggest that postsynaptic response to dopamine can recover at 12 months abstinence.

Dopamine is not the only neurotransmitter affected by MA. Bustamante et al (2002) observed chronic changes after repeated acute MA binges in rats including a decreased release of dopamine in both the neostriatum and substantia nigra and increases in GLU and GABA levels. The authors concluded that repeated MA administration might alter dopamine homeostasis and perhaps overstimulation of striatal GLU NMDA receptors. Alterations in GABA and GLU are likely to be important to the behavioral changes observed following MA exposure in animals. MA-induced alterations in nigrostriatal dopamine can influence GABAergic and glutamatergic transmission downstream and produce a variety of motor disturbances. Floran et al (1977) reported that acute MA administration in rats decreased GABA levels via their direct interaction within the striatal dopamine subsystem. Burrows and Meshul (1999) reported striatal and pallidal decreases in GABA immunoreactivity following 1 week of MA exposure; however, GABAergic immunoreactivity increased following prolonged exposure for up to 4 weeks. Prolonged exposure to MA altered presynaptic GABA immunolabeling and increased GLU terminal size in both the striatum and globus pallidus. The authors concluded that these dynamic changes within the striatopallidal pathway were similar to those found following nigrostriatal lesions in animals in which dopamine loss alters GABAergic striatopallidal neurotransmission.

There are reports demonstrating sparing of GABAergic systems in rats exposed to MA (Chapman et al, 2001). Kaiya et al (1983) found that 16 days of MA administration did not change GABA levels in the striatum, whereas Kamata and Kameyama (1986) reported that 6 days of MA exposure, twice daily, increased striatonigral GABA activity. Discrepancies in how MA affects GABA levels may be explained by differences in exposure duration and/or where GABA levels are measured. Nonetheless, it is likely that MA decreases striatal GABA neurotransmission acutely.

Change in temperature regulation has been shown to mediate the neurotoxic effects of MA, with higher body temperatures facilitating neurotoxicity (Cadet et al, 2003). In rodents, holding the body temperature constant can markedly reduce the toxic effects of MA on the basal ganglia (Burrows and Meshul, 1999). Bowyer et al (1994) and others (Fukumura et al, 1998) have shown that MA-induced hyperthermia is correlated with neurotransmitter reduction in the adult, but not in the developing rat. Cappon et al (1997) argued that induction of hyperthermia is a requisite for the expression of MA-induced striatal dopamine neurotoxicity. There is some evidence that DAT may play an important role in the expression of MA-induced hyperthermia and neurotoxicity (Xie et al, 2000; Broening et al, 2005). Broening et al (2005) found that coadministration of dopamine $\mathrm{D}_{1}$ and $\mathrm{D}_{2}$ receptor antagonists attenuated both the MA-induced reduction in striatal dopamine and hyperthermia in rats. However, when animals were subjected to ambient temperatures known to facilitate hyperthermia, only the $\mathrm{D}_{2}$ receptor antagonist continued to provide protection. The authors concluded that $\mathrm{D}_{2}$ receptor antagonist eticlopride blocked striatal DAT activity and inhibited presynaptic DA release. Thus, the mechanism thought to underlie MA-induced hyperthermia and dopamine neurotoxicity may involve $D_{2}$ receptor-mediated upregulation of DAT activity.

In summary, MA alters both excitatory and inhibitory neurotransmitter systems in the brain. Its predominant acute effect is to increase nigrostriatal dopamine. Elevated nigrostriatal dopamine would manifest as increased locomotor activity and stereotypy in animals and hyperkinesia in humans. Elevated nigrostriatal dopamine, especially involving the $D_{2}$ receptor system, leads to a decrease in striatopallidal GABA level. This pathophysiology can produce a loss of inhibitory regulation and hyperkinetic movements. It has been proposed that prolonged or chronic MA exposure may have neurotoxic effects on striatal dopamine neurons manifesting as reduced locomotor behavior or parkinsonism. These neurotoxic effects manifest anatomically by reactive gliosis and decreases in evoked dopamine metabolites. Additionally, environmental changes, such as hyperthermia, may play an important role in MA neurotoxcity whether direct or indirect. The ameliorative effects of abstinence are largely unknown. There is literature to support partial recovery in monoamine levels (Friedman et al, 1998; Melega et al, 1997) in rats when measured 6-9 months following acute exposure to MA. Yet, Cass and Manning (1999) reported full recovery in potassium-evoked outflow of dopamine in the striatum 12 months after acute MA exposure, suggesting a possible 
role of sensitization as a homeostatic mechanism for recovery after a neurotoxic MA insult. A study in primates indicated persistent dopamine and serotonin depletion up to 4 years following high-dose MA treatment (Woolverton et $a l, 1989)$. It has been speculated that age of the animal may be an important determinant in how much recovery of neurotransmitter function is observed with long-term abstinence (Seiden et al, 1993) with older animals showing less recovery.

\section{Clinical Studies}

Functional neuroimaging approaches are beginning to shed light on the effects of MA exposure on striatal neurochemistry in humans. Of particular relevance to this review are the positron emission tomography (PET) studies of striatal DAT density (Volkow et al, 1999, 2001b), dopamine receptor occupancy (Volkow et al, 2001a), and regional brain glucose metabolism (Volkow et al, 2001c; Wang et al, 2004). PET studies of DAT availability implicate the striatum in both psychomotor and cognitive disturbances associated with MA abuse. PET studies have shown up to a $25 \%$ reduction in DAT in the caudate and putamen among MA users (McCann et al, 1998; Volkow et al, 2001b). Findings indicate that the striatum may be more vulnerable to the neurotoxic effects of MA and may be slower to recover following abstinence than the thalamus (Wang et al, 2004).

Ernst et al (2000) using proton magnetic resonance spectroscopy reported a 5\% decrease in $\mathrm{N}$-acetylaspartate (a marker of long-term neuronal damage) in the basal ganglia and an 11-13\% increase in myo-inositol and cholinecontaining compounds (markers of glial abnormality) in frontal gray matter in abstinent MA users. The decreased $\mathrm{N}$-acetylaspartate and increased myo-inositol suggest glial proliferation secondary to neuronal damage. It is interesting that neuronal damage was present in subjects abstinent for as long as 21 months. While these findings are generally consistent with the preclinical findings on neuronal damage, they do not provide the necessary detail to help localize the damage to a particular basal ganglia pathway or to identify region-specific vulnerabilities to chronic MA exposure in humans. However, Chang et al (2005) recently reported both striatal and pallidal enlargement in abstinent MA abusers based on structural MRI. Their MA abusers showed larger globus pallidus (9.6\%) and putamen $(9.9 \%)$ volumes compared to age and gender comparable controls. While the specific etiology of the structural enlargement is uncertain, the authors attributed their findings to MAinduced striatal injury leading to inflammation and reactive gliosis. These studies contribute to the general notion that long-term MA exposure in humans and rodents leads to striatal and pallidal injury manifested by tissue inflammation and gliosis.

\section{MOTOR DYSFUNCTION FOLLOWING MA}

\section{Preclinical Studies}

In the mid-1970s Baker et al (1976) reported that intracaudate injections of $\mathrm{D}$-amphetamine led to motor hyperactivity in cats. Injection of $\mathrm{D}$-amphetamine initiated tremorous paw movements while administration of dopamine into the striatum attenuated the response. Studies have since highlighted the fact that amphetamines, including MA, produce hyperkinetic states in animals characterized by stereotypies (Wallace et al, 1999; Kuczenski and Segal, 2001), increased locomotor responses (Riviere et al, 1999; Szumlinski et al, 2000), and prolonged dosedependent reaction during a choice RT task (Mishima et al, 2002; Sabol et al, 2003).

In general, these conditions are dose dependent (Riviere et al, 1999) and occur within a few days following MA injection (Timar et al, 2003). Segal and Kuczenski (1997) found that rats exposed to escalating high-dose binges exhibited increased locomotor activity compared to rats exposed to intermittent dosing of MA. In their study, stereotypies were related to cumulative dose rather than dosing schedule. Additional support for the importance of dopamine in the development of MA-induced motor abnormalities comes from studies of dopamine knockout mice. These animals exhibit a generalized state of catatonia and insensitivity of the response to MA (Nishii et al, 1998).

Consideration has been given to the selected effects of MA on dopamine receptor subpopulations and their respective behavioral attributes. G-protein coupled dopamine receptors have been classified into two families based on their effects on adenylate cyclase. Members of the dopamine D1 receptor family stimulate adenylate cyclase when stimulated, whereas members of the D2 family inhibit or have no effect on adenylate cyclase. D2 receptors are 2 to 3 times more sensitive than D1 receptors to dopamine (Missale et al, 1998). The animal literature suggests that MA alters both D1 and D2 dopamine receptor functions; however, there is some evidence that the effects on the D1 and D2 striatopallidal pathways may differ.

With regard to specific changes to the dopamine D1 (direct striatopallidal) system, MA administration has been shown to increase expression of kappa opioid receptors in the striatum and to decrease dopamine D1 receptors Adams et al (2003) reported an increased dynorphin release in striatal patch division in rats following MA administration. Cadet et al (1998) found that MA decreases striatal D1 receptors. Studies of transgenic D1 knockout mice report diminished effects of psychostimulants on striatal neurons, particularly in the striosomal compartment (Moratalla et al, 1996). Two studies reported direct effects of kappa receptor agonists on MA-induced dopamine release. Kuribara and Uchihashi (1994) found that coadministration of a kappa receptor agonist reduced striatal dopamine levels and inhibited MA-induced locomotor activity. Similarly, kappa receptor agonists potentiated striatal dopamine loss (Johnson-Davis et al, 2003) and can normalize the increased behavioral sensitivity induced by MA administration (Toyoshi et al, 1996). Additional evidence implicating a striatal D1 receptor mechanism stems from the work of Hanson et al (2002), who found increased expression of substance $P$ in the substantia nigra following acute MA exposure that was blocked by a dopamine D1 receptor agonist.

While the evidence supporting a dopamine D1 mechanism for the behavioral consequences of MA is compelling, there is evidence to the contrary. For example, Gifford et al (2000) found that MA-induced striatal dopamine release

Neuropsychopharmacology 
interfered with D2 but not D1 receptor tracer binding. It has been argued that this effect may be due to the dramatic decrease in sensitivity of the D1 receptor to dopamine following MA exposure rather than competition for receptor binding sites Schoffelmeer et al (1994).

With regard to the specific changes to the dopamine D2 (indirect striatopallidal) system, MA administration has been shown to decrease D2 receptor binding affinity and increase expression of mu opioid receptors in the striatum. As noted above, Gifford et al (2000) found that MA-induced striatal dopamine release interfered with D2 receptor tracer binding. Doudet and Holden (2003) also reported that MA competed for the same D2 receptors as the dopamine antagonist, raclopride. Magendzo and Bustos (2003) demonstrated in rats that acute MA exposure resulted in increased transcription of mu opioid receptor and delta opioid receptor in the ventral tegmental area, which corresponded with an acute sensitization to MA. These results implicate the indirect striatopallidal pathway because of the colocalization of enkephalin (via the $\mathrm{mu}$ receptor) and GABA. MA-induced locomotor hyperactivity and stereotypy require normal D2 receptor function (Sano et al, 2003; Glickstein and Schmauss, 2004). This observation suggests that MA-related hyperkinesia may be less pronounced in aged compared with younger animals.

Preclinical studies show that MA administration can inhibit striatal activity via the dopamine D2 system and facilitate striatal activity via the dopamine D1 system. The results from studies of the opioid peptides and their receptors implicate the striatopallidal system in the pathogenesis of MA-induced behavioral changes. Specifically, increased sensitivity of the mu receptors to MA implicates the indirect striatopallidal system; whereas increased expression of kappa receptors implicates the direct striatopallidal system. The majority of the literature on dopamine receptor mechanisms in MA-induced behavioral change involved specific pharmacologic manipulations of the MA response. While these methods are useful for distinguishing the relevance of a particular dopamine subsystem (eg D1 or D2), these pharmacologic manipulations impose changes to neuronal systems that, even in the absence of MA coadministration, can alter motor behavior. In fact, opioid peptides have been employed for years as a potential adjunctive treatment for Parkinson's disease (Giuffra et al, 1993; Hille et al, 2001) and its complications (Henry and Brotchie, 1996). Nevertheless, this work has led to a greater understanding of the role of MA in behavioral disturbances regulated by the dopamine via the direct and indirect striatopallidal GABAergic pathways and their translation to movement disorders humans.

\section{Clinical Studies}

Preclinical findings from numerous studies utilizing a variety of approaches summarized above implicate both the direct and indirect striatopallidal pathways in the pathogenesis of MA-related movement disorders. MA has been shown to influence the dopamine regulatory systems in the basal ganglia both presynaptically (Gifford et al, 2000) and postsynaptically (Cadet et al, 1998), and can compromise both excitatory (via a D2 receptor mechanism) and inhibitory (via a D1 receptor mechanism) functions (Toyoshi et al, 1996; Hanson et al, 2002). Contemporary models of basal ganglia function predict that dysfunctions within the nigrostriatal or striatopallidal circuits produce not only a failure to facilitate desired movements, but also failure to inhibit unwanted movements (Mink, 2003). The results from preclinical and clinical studies show that MA exposure increases nigrostriatal dopamine acutely, can decrease dopamine levels chronically, and can indirectly decrease GABAergic neurotransmission. In theory, disruption of excitatory or inhibitory striatopallidal neurotransmission by diminished or increased dopaminergic regulation would manifest as parkinsonism or hyperkinesia, respectively. Yet, the question remains: do the animal studies of MA-induced motor dysfunction elucidate the clinical manifestations in individuals who abuse MA? That is, is the nature of the movement disorder observed in MA abusers consistent with the mechanisms revealed by animal studies?

Clinically, MA-related movement disorders fall into three categories: acute reactions in the form of hyperkinesia, and persistent effects in the form of parkinsonism and psychomotor disturbances. Unfortunately, the current literature consists of very few systematic studies of MArelated movement disorders such that epidemiologic trends are not possible.

Our review of the literature turned up only three case reports on stimulant abuse and hyperkinetic movement disorders (Mattson and Calvery, 1968; Lundh and Tunving, 1981; Sperling and Horowitz, 1994) and only one of these pertained directly to MA (Sperling and Horowitz, 1994). This is surprising because of the overwhelming evidence from animal studies that MA exposure induced increased locomotor activity and stereotypies. In the human reports, the movement disorders were described as involuntary movements of the face, arms, legs, and trunk that often disappeared when engaged in voluntary movements. At times, the movements were rapid and ballistic and affected gait. In some individuals, the abnormal movements occurred during abstinence and persisted for a year or longer following discontinuation (Lundh and Tunving, 1981). Sperling and Horowitz (1994) described a 50-yearold male who presented to an emergency room with choreiform movements of the upper extremities, head, and neck following use of crystallized MA. The patient also exhibited mild psychosis and agitation leading the authors to conclude that the motor and behavioral symptoms were related to the central dopaminergic effects of MA. Symptoms returned to normal following a 7-day hospitalization.

Moszczynska et al (2004) argued that parkinsonism may not be a feature of MA abuse in humans. Their argument was based on autopsy data showing greater reduction in dopamine levels in the caudate nucleus (61\% reduction $v s$ controls) compared with the putamen (50\% reduction) in subjects testing positive for MA. The authors concluded that their MA subjects probably did not exhibit parkinsonism because dopamine levels had not dropped to levels sufficient to produce motor impairment; however, in the absence of clinical records supporting normal motor functions, the question of whether MA abuse is a risk factor for parkinsonism remains unanswered. 
Among the four published studies on MA-induced reductions in dopamine neurotransmission in humans, none included information on the presence of parkinsonian motor signs (Wilson et al, 1996; Volkow et al, 2001a; McCann et al, 1998; Moszczynska et al, 2004). The PET imaging studies show losses of $25 \%$ for DAT and $10 \%$ for dopamine D2 receptors in the putamen (Volkow et al, 2001a; McCann et al, 1998). The post-mortem brain tissue studies show losses as high as 53\% (Wilson et al, 1996; Moszczynska et al, 2004). However, these studies do not offer compelling evidence that MA abuse in humans necessarily produces parkinsonism. While it is likely that reductions in striatal dopamine levels may be insufficient to produce clinical signs of parkinsonism, without prevalence figures on clinical manifestations in MA abusers, this remains an open question.

MA has been shown to produce psychomotor disturbances based on the grooved pegboard test (Volkow et al, 2001d), trailmaking tests (Kalechstein et al, 2003; Simon et al, 2000), finger tapping (Toomey et al, 2003), and reaction time (Richards et al, 1993) tests. It is not clear, however, if these disturbances are secondary effects of subtle parkinsonism or hyperkinetic conditions or if they are independent of extrapyramidal disorders and reflect disturbances in planning, attention, or executive function. Chang et al (2002) suggested that psychomotor slowing in MA users might represent a subclinical form of parkinsonism.

Using PET, Volkow et al (2001d) observed a relationship between performance on the grooved pegboard and timed gait tasks and loss of DAT in the striatum in abstinent (12 months) MA abusers. Slower performance times were associated with lower levels of striatal DAT availability. Kalechstein et al (2003) reported that abstinent MA users had significantly poorer performance on measures of psychomotor speed (symbol digit modalities test) compared with controls. Subjects in this study were assessed at least 5 days following a positive urine test for MA. It is difficult to generalize the results from these two studies with regard to psychomotor impairment because of differences in the tasks used to assess psychomotor speed, lack of adequate control groups, and difference in duration of abstinence. Nonetheless, these findings indicate that psychomotor changes can persist beyond the early withdrawal phase following MA use.

Clinical studies suggest that the psychomotor disturbances associated with MA may not be due to basic motor processes, but rather involve higher-level motor processes such as set shifting, planning, and manipulation of information (Simon et al, 2000). This conclusion is consistent with the findings by Moszczynska et al (2004) that the neurotoxic effects of prolonged exposure to MA are more pronounced in the cognitive areas of the striatum (ie caudate) than the pure motor areas (ie putamen).

Toomey et al (2003) evaluated neuropsychological performance in 50 twin pairs. Subjects were selected for study because one member used stimulants weekly for at least 1 year and the twin sibling never used stimulants. Amphetamines were reported to be the drug of abuse on 40 of the 50 twin pairs. Subjects reported abstinence of at least 1 year prior to participating in the study. Several psychomotor tests including trailmaking test, grooved pegboard test, and finger tapping were part of their comprehensive battery. The investigators found significantly poorer performance among the stimulant abusers compared with the nonabusing siblings on the trailmaking test (part A), grooved pegboard test, and finger-tapping test. These results confirm the presence of long-term residual deficits in psychomotor function associated with amphetamine abuse.

\section{DO PRECLINICAL STUDIES OF MA-INDUCED MOTOR ABNORMALITIES TRANSLATE TO AN OBSERVABLE CLINICAL PHENOTYPE?}

In humans, MA abuse has been shown to induce hyperkinetic movement disorders such as chorea and tics and there are several reports of impaired psychomotor performance. However, we could find no reports of clinically apparent parkinsonism induced by MA exposure. This suggests that while prolonged exposure to MA can produce alterations in striatal dopamine physiology in humans, these changes do not always lead to an observable parkinsonian phenotype. There are several explanations for this. It may be argued that parkinsonian symptoms are too subtle to be readily observed and that sensitive measurement tools are needed to indicate more widespread motor effects of MA abuse. However, it may also be argued that MA-induced neurotoxicity is different than that seen in Parkinson's disease or that other biological or environmental factors mitigate the expression of parkinsonism in MA-induced neurotoxicity that are not present in Parkinson's disease. Based on the preclinical literature reviewed above, we considered at least three factors that could explain the lack of an MA-induced parkinsonian phenotype in humans. These include the role of nicotine, tolerance to the neurotoxic effects of MA, and absence of comorbid hyperthermia.

Regarding nicotine, nearly all MA abusers smoke heavily. While prevalence data for comorbid nicotine among MA users is not known, published data from a study of injection drug users found that $91 \%$ were current cigarette smokers (Clarke et al, 2001). It has been shown repeatedly that nicotine reduces the risk of Parkinson's disease (Baron, 1986; Morens et al, 1995). Nicotine has been shown to prevent MA-induced nigrostriatal damage in rats (Maggio et al, 1998) via a mechanism thought to involve neurotropic factors and can reduce the locomotor sensitivity to MA in mice (Kuribara, 1999). Nicotine also inhibits monoamine oxidase (Berlin and Anthenelli, 2001; Castagnoli et al, 2002) enabling the greater bioavailability of striatal dopamine. Such nicotine-related mechanisms could compensate for MA-induced neurotoxic effects of dopamine neurotransmission and delay or minimize the development of parkinsonian motor signs.

The development of tolerance to the neurotoxic effects of MA may also explain the lack of an observable parkinsonian phenotype in humans. It has been shown that chronic MA exposure in escalating doses leads to behavioral and neurochemical sensitization (Gygi et al, 1996; Itzhak and Ali, 2002; Segal et al, 2003). Thomas and Kuhn (2005) observed that intermittent exposure to low doses of MA attenuated the microglial response and led to the development of tolerance to MA toxicity in mice. Animals pre- 
exposed to MA showed less neurotoxicity (eg microglial activation) after MA exposure than acutely challenged mice. They concluded that this tolerance effect, at the level of the dopamine nerve ending, might serve as a neuroprotection response. If this effect can be observed across species, it might explain the lack of observable parkinsonism among intermittent MA users.

Hyperthermia is thought to mediate the neurotoxic effects of MA. Higher body temperatures facilitate neurotoxicity in MA-exposed animals possibly through an oxidative stress mechanism (Cadet et al, 2003). To our knowledge, there have been no studies clarifying the role of body temperature on clinical manifestation of MA abuse in humans. Studies of the behavioral effects of MA abuse in humans do not obtain contemporary information of body temperature. Insofar as hyperthermia is an important factor in the pathogenesis of MA-induced neurochemical changes (Xie et al, 2000; Broening et al, 2005), it would also seem that hyperthermia would be critical to the expression of behavioral abnormalities, such as parkinsonism. Considering other druginduced conditions strengthens this argument. For example, hyperthermia and parkinsonism cooccur in neuroleptic malignant syndrome and serotonin syndrome (Gurrera, 2002; Mizuno et al, 2003). It is thought that parkinsonian rigidity and fever stem from a mechanism involving the balance of dopamine and serotonin in the basal ganglia and brainstem (Meigal and Lupandin, 2005). It is possible that MA-induced parkinsonism may depend on a disrupted thermoregulatory mechanism. Epidemiological studies are necessary to test whether environmental conditions are associated with the presence of a parkinsonian phenotype among MA users.

The primary question posed in this review concerns the ability of preclinical research on MA administration to inform the clinical condition. The preceding paragraphs highlight several important distinctions between preclinical and clinical findings that lead to two conclusions: (1) neurobiologic mechanisms underlying preclinical models of MA-induced hyperkinetic movement disorders correspond directly to the clinical presentation following acute exposure to MA; and (2) neurobiologic mechanisms underlying preclinical models of MA-induced parkinsonism do not necessarily translate to the clinical presentation, given the currently available research.

\section{Conclusions}

In animals, MA produces motor effects following acute and chronic exposure, suggesting separate mechanisms involving increase DA release and neurotoxicity, respectively. Effects of MA neurotoxicity include hyperthermia, locomotor abnormalities. Studies show that rodents develop tolerance to the neurotoxic effects, particularly during intermittent dosing regimens. In humans, acute MA exposure produces hyperkinetic motor effects similar to laboratory animals; however, the behavioral effects of longer-term neurotoxicity are not obvious. Significant differences in the expression of neurotoxicity and presence of multiple environmental and pharmacologic confounds may account for the lack of a parkinsonian phenotype in humans despite evidence of altered dopamine function. We argue that the results from animal studies of chronic MA exposure do not necessarily translate to the clinical phenotype because of the protective effects of nicotine, an absence of hyperthermia, and tolerance stemming from intermittent use. Furthermore, the control of experimental variables in rodent research is very high, while human research will always be associational. It is also possible that the lack of an observable parkinsonian phenotype with chronic MA use is simply due to the use of insensitive measurements.

The key question stemming from this review is how is it that MA abuse leads to persistent damage to motor areas of the basal ganglia in humans, but that there are only few domains that show persistent behavioral deficits. Future studies can address this question. For example, because of its neuroprotective properties, it is important to control for the amount and extent of comorbid nicotine consumption when estimating prevalence of persistent MA-induced motor abnormalities. The question of whether hyperthermia is important in the pathophysiology of MA-induced dopamine neurotoxicity can be addressed by documenting body temperature at the time of the behavioral assessments. It remains unknown if comorbid fever emerged more often in a subgroup of MA abusers and whether these individuals are at greater risk for developing persistent parkinsonism. To address the question of whether individuals develop tolerance to the neurotoxic effects of MA, it is important to document patterns and time course of MA exposure. Parkinsonian motor disturbances may present to a greater extent among binge users compared to infrequent users. Lastly, studies can employ sensitive instrumental measures of motor function to detect subthreshold parkinsonian motor disturbances among chronic MA users. We have previously demonstrated that electromechanical devices and computerized analyses can detect mild subclinical parkinsonian motor signs that are overlooked using conventional observational methods (Caligiuri et al, 1993; Cortese et al, 2005).

\section{ACKNOWLEDGEMENTS}

This work was supported by a research grant from NIDA (2 P01- DA012065), the Department of Veteran Affairs VISN22 Mental Illness Research, Education, and Clinical Center, and UCSD School of Medicine Independent Study Program.

\section{REFERENCES}

Abekawa T, Ohmori T, Koyama T (1994). Effects of repeated administration of a high dose of methamphetamine on dopamine and glutamate release in rat striatum and nucleus accumbens. Brain Res 643: 276-281.

Adams DH, Hanson GR, Keefe KA (2003). Distinct effects of methamphetamine and cocaine on preprodynorphin messenger RNA in rat striatal patch and matrix. J Neurochem 84: 87-93.

Albin RL, Young AB, Penney JB (1989). The functional anatomy of basal ganglia disorders. Trends Neurosci 12: 366-375.

Alexander GE, Crutcher MD, DeLong MR (1990). Basal gangliathalamocortical circuits: parallel substrates for motor, oculomotor, 'prefrontal' and 'limbic' functions. Prog Brain Res 85: 119-146.

Alkhani A, Lozano AM (2001). Pallidotomy for Parkinson's disease: a review of contemporary literature. J Neurosurg 94: $43-49$. 
Baker WW, Zivanovic D, Malseed RT (1976). Tremorogenic effects of intracaudate D-amphetamine and their suppression by dopamine. Arch Int Pharmacodyn Ther 2: 271-281.

Balogh B, Molnar E, Jakus R, Quate L, Olverman HJ, Kelly PAT et al (2004). Effects of a single dose of 3,4-methylenedioxymethamphetamine on circadian patterns, motor activity and sleep in drug-naïve rats and rats previously exposed to MDMA. Psychopharmacology 173: 296-309.

Baron JA (1986). Cigarette smoking and Parkinson's disease. Neurology 36: 1490-1495.

Berlin I, Anthenelli RM (2001). Monoamine oxidases and tobacco smoking. Int J Neuropsychopharmacol 4: 33-42.

Bowyer JF, Davies DL, Schmued L, Broening LW, Newport GD, Slikker W et al (1994). Further studies of the role of hyperthermia in methamphetamine neurotoxicity. J Pharmacol Exp Ther 268: 1571-1580.

Bradshaw JL (2001). Development Disorders of the Frontostriatal System: Neuropsychological, Neuropsychiatric and Evolutionary Perspectives. Psychology Press: Philadelphia.

Broening HW, Morford LL, Vorhees CV (2005). Interactions of dopamine $D_{1}$ and $D_{2}$ receptor antagonists with D-methamphetamine-induced hyperthermia and striatal dopamine and serotonin reductions. Synapse 56: 84-93.

Brooks DJ, Piccini P, Turjanski N, Samuel M (2000). Neuroimaging of dyskinesia. Ann Neurol 47(Suppl 1): 154-158.

Burrows KB, Meshul CK (1999). High-dose methamphetamine treatment alters presynaptic GABA and glutamate immunoreactivity. Neuroscience 90: 833-850.

Bustamante D, You ZB, Castel MN, Johansson S, Goiny M, Terenius L et al (2002). Effect of single and repeated methamphetamine treatment on neurotransmitter release in the substantia nigra and neostriatum in the rat. J Neurochem 83: 645-654.

Cadet JL, Jayanthi S, Deng X (2003). Speed kills: cellular and molecular bases of methamphetamine-induced nerve terminal degeneration and neuronal apoptosis. FASEB J 17: 1775-1788.

Cadet JL, Ladenheim B, Hirata H (1998). Effects of toxic doses of methamphetamine on dopamine D1 receptors in the mouse brain. Brain Res 786: 240-242.

Caligiuri MP, Lohr JB, Jeste DV (1993). Parkinsonism in neurolepticnaive schizophrenic patients. Am J Psychiat 150: 1343-1348.

Cappon GD, Morford LL, Vorhees CV (1997). Ontogeny of methamphetamine-induced neurotoxicity and associated hyperthermic response. Dev Brain Res 103: 155-162.

Cass WA, Manning MW (1999). Recovery of presynaptic dopaminergic functioning in rats treated with neurotoxic doses of methamphetamine. J Neurosci 19: 7653-7660.

Castagnoli K, Steyn SJ, Magnin G, Van der Schyf CJ, Fourie I, Khalil A et al (2002). Studies of the interactions of tobacco leaf and tobacco smoke constituents and monoamine oxidase. Neurotox Res 4: 151-160.

Chang L, Ernst T, Speck O, Grob CS (2005). Additive effects of HIV and chronic methamphetamine use on brain metabolite abnormalities. Am J Psychiatry 162: 361-369.

Chang L, Ernst T, Speck O, Patel H, DeSilva M, Leonido-Yee M et al (2002). Perfusion MRI and computerized cognitive test abnormalities in abstinent methamphetamine users. Psychiatr Res 114: 65-79.

Chapman DE, Hanson GE, Kesner RP, Keefe KA (2001). Long-term changes in basal ganglia function after a neurotoxic regimen of methamphetamine. J Pharmcol Exp Ther 296: 520-527.

Clarke JG, Stein MD, McGarry KA, Gogineni A (2001). Interest in smoking cessation among injection drug users. Am J Addict 10: 159-166.

Cortese L, Caligiuri MP, Malla AK, Manchanda R, Takhar J, Haricharan R (2005). Relationship of neuromotor disturbances to psychosis symptoms in first-episode neuroleptic-naïve schizophrenia patients. Schizophr Res 75: 65-75.
Davidson C, Gow AJ, Lee TH, Ellinwood EH (2001). Methamphetamine neurotoxicity: necrotic and apoptotic mechanisms and relevance to human abuse and treatment. Brain Res Rev 36: 1-22.

DeLong MR (1990). Primate models of movement disorders of basal ganglia origin. Trends Neurosci 13: 281-285.

Dostrovsky JO, Hutchison WD, Lozano AM (2002). The globus pallidus, deep brain stimulation, and Parkinson's disease. Neuroscientist 8: 284-290.

Doudet DJ, Holden JE (2003). Raclopride studies of dopamine release: dependence on presynaptic integrity. Biol Psychiatry 54: 1193-1199.

Ernst T, Chang L, Leonido-Yee M, Speck O (2000). Evidence for long-term neurotoxicity associated with methamphetamine abuse: a 1H MRS study. Neurology 54: 1344-1349.

Escubedo E, Guitart L, Sureda FX, Jimenez A, Pubill D, Pallas M et al (1998). Microgliosis and down-regulation of adenosine transporter induced by methamphetamine in rats. Brain Res 14: 120-126.

Floran B, Floran L, Sierra A, Aceves J (1997). D2 receptor-mediated inhibition of GABA release by endogenous dopamine in the rat globus pallidus. Neurosci Lett 237: 1-4.

Friedman SD, Castaneda E, Hodge GK (1998). Long-term monoamine depletion, differential recovery, and subtle behavioral impairment following methamphetamine-induced neurotoxicity. Pharmacol Biochem Behav 61: 35-44.

Fukumara M, Cappon GD, Broening HW, Vorhees CV (1998). Methamphetamine-induced dopamine and serotonin reductions in the neostriatum are not gender specific in rats with comparable hypothermic responses. Neurotoxicol Teratol 20: 441-448.

Gibb JW, Johnson M, Hanson GR (1990). Neurochemical basis of neurotoxicity. Neurotoxicology 11: 317-321.

Gifford AN, Park MH, Kash TL, Herman LM, Park E, Gatley SJ et al (2000). Effect of amphetamine-induced dopamine release on radiotracer binding to D1 and D2 receptors in rat brain striatal slices. Arch Pharmacol 362: 413-418.

Giuffra M, Mouradian MM, Davis TL, Ownby J, Chase TN (1993). Dynorphin agonist therapy of Parkinson's disease. Clin Neuropharmacol 16: 444-447.

Glickstein SB, Schmauss C (2004). Focused motor stereotypies do not require enhanced activation of neurons in striosomes. J Comp Neurol 469: 227-238.

Gurrera RJ (2002). Is neuroleptic malignant syndrome a neurogenic form of malignant hyperthermia? Clin Neuropharmacol 25: 183-193.

Guilarte TR, Nihei MK, McGlothan JL, Howard AS (2003). Methamphetamine-induced deficits of brain monoaminergic neuronal markers; distal axotomy or neural plasticity. Neuroscience 122: 499-513.

Gygi MP, Gygi SP, Johnson M, Wilkins DG, Gibb JW, Hansen GR (1996). Mechanisms for tolerance to methamphetamine effects. Neuropsychopharmacology 35: 751-757.

Hanson GR, Bush L, Keefe KA, Alburges ME (2002). Distinct responses of basal ganglia substance $\mathrm{P}$ systems to low and high doses of methamphetamine. J Neurochem 82: 1171-1178.

Henry B, Brotchie JM (1996). Potential of opioid antagonists in the treatment of levodopa-induced dyskinesias in Parkinson's disease. Drugs Aging 9: 149-158.

Henry B, Duty S, Fox SH, Crossman AR, Brotchie M (2003). Increased striatal pre-proenkephalin B expression is associated with dyskinesia in Parkinson's disease. Exp Neurol 183: $458-468$.

Hille CJ, Fox SH, Maneuf YP, Crossman AR, Brotchie JM (2001). Antiparkinsonian action of a delta opioid agonist in rodent and primate models of Parkinson's disease. Exp Neurol 172: 189-198.

Horak FB, Anderson ME (1984). Influence of globus pallidus on arm movements in monkeys. I. Effects of kainic acid-induced lesions. J Neurophysiol 52: 290-304. 
Itzhak Y, Ali SF (2002). Behavioral consequences of methamphetamine-induced neurotoxicity in mice: relevance to the psychopathology of methamphetamine addiction. Ann NY Acad Sci 965: $127-135$.

Johnson-Davis KL, Hanson GR, Keefe KA (2003). Lack of effect of kappa-opioid receptor agonism on long-term methamphetamine-induced neurotoxicity. Neurotox Res 5: 273-281.

Kaiya H, Takeuchi K, Yoshida H, Kondo T, Sanpei F, Okada Y et al (1983). Effects of subchronic treatment of methamphetamine and haloperidol on the rat brain levels of GABA, glutamate, and aspartate. Folia Psychiatr Neurol Jpn 37: 107-113.

Kalechstein AD, Newton TF, Green M (2003). Methamphetamine dependence is associated with neurocognitive impairment in the initial phases of abstinence. J Neuropsychiatr Clin Neurosci 15: 215-220.

Kamata K, Kameyama T (1986). Effect of chronic administration of methamphetamine on responsiveness of substantia nigra zona reticulate neurons to GABA or a GABA agonist in rats. Arch Pharmacol 334: 458-462.

Kita T, Wagner GC, Nakashima T (2003). Current research on methamphetamine-induced neurotoxicity: animal models of monamine disruption. J Pharmacol Sci 92: 178-195.

Kogan FJ, Nichols WK, Gibb JW (1976). Influence of methamphetamine on nigra and striatal tyrosine hydroxylase activity and on striatal dopamine levels. Eur J Pharmacol 36: 363-371.

Kuczenski R (1983). Biochemical action of amphetamine and stimulants. In: Cress I (ed). Stimulants: Neurochemical, Behavioral and Clinical Perspectives. Raven Press: New York. pp 21-61.

Kuczenski R, Segal DS (2001). Caudate-putamen and nucleus accumbens extracellular acetylcholine response to methamphetamine binges. Brain Res 923: 32-38.

Kuribara H (1999). Does nicotine modify the psychotoxic effect of methamphetamine? Assessment in terms of locomoter sensitization in mice. $J$ Toxicol Sci 24: 55-62.

Kuribara H, Uchihashi Y (1994). Effects of dopamine antagonism on methamphetamine sensitization: evaluation by ambulatory activity in mice. Pharmacol Biochem Behav 47: 101-106.

Lichter DG, Cummings JL (2001). Frontal-Subcortical Circuits in Psychiatric and Neurologic Disorders. Guildford Press: New York.

Lozano AM, Lang AE (2001). Pallidotomy for Parkinson's disease. Adv Neurol 86: 413-420.

Lundh H, Tunving K (1981). An extrapyramidal choreiform syndrome caused by amphetamine addiction. J Neurol Neurosurg Psychiatr 44: 728-730.

Magendzo K, Bustos G (2003). Expression of amphetamineinduced behavioral sensitization after short- and long-term withdrawal periods: participation of $\mu$ - and $\partial$-opioid receptors. Neuropsychopharmacology 28: 468-477.

Maggio R, Riva M, Vaglini F, Formai F, Molteni R, Armogida M et al (1998). Nicotine prevents experimental parkinsonism in rodents and induced striatal increase of neurotropic factors. J Neurochem 71: 2439-2446.

Mattson R, Calvery JR (1968). Dextroamphetamine-sulfate-induced dyskinesias. JAMA 204: 108-110.

McCann UD, Wong DF, Yokoi F, Villemagne V, Dannals RF, Ricaurte GA (1998). Reduced striatal dopamine transporter density in abstinent methamphetamine and methcathinone users: evidence from positron emission tomography studies with [11C]WIN-35,428. J Neurosci 18: 8417-8422.

Meigal A, Lupandin Y (2005). 'Thermoregulation-dependent component' in pathophysiology of motor disorders in Parkinson's disease? Pathophysiology 11: 187-196.

Melega WP, Raleigh MJ, Stout DB, Lacan G, Huang S, Phelps ME (1997). Recovery of striatal dopamine function after acute amphetamine- and methamphetamine-induced neurotoxicity in the vervet monkey. Brain Res 766: 113-120.
Miller DB, O'Callaghan JP, Ali SF (2000). Age as a susceptibility factor in the striatal dopaminergic neurotoxicity observed in the mouse following substituted amphetamine exposure. Ann NY Acad Sci 914: 194-207.

Mink JW (2003). The basal ganglia and involuntary movements. Arch Neurol 60: 1365-1368.

Mink JW, Thatch WT (1993). Basal ganglia intrinsic circuits and their role in behavior. Curr Opin Neurobiol 3: 950-957.

Mishima K, Fujii M, Aoo N, Yoshikawa T, Fukue Y, Honda Y et al (2002). The pharmacological characterization of attentional processes using a two-lever choice reaction time task in rats. Biol Pharm Bull 25: 1570-1576.

Missale C, Nash SR, Robinson SW, Jaber M, Caron MG (1998). Dopamine receptors: from structure to function. Physiol Rev 78: $189-225$.

Mizuno Y, Takubo H, Mizuta E, Kuno S (2003). Malignant syndrome in Parkinson's disease; concept and review of the literature. Parkinsonism Relat Dis 9: S3-S9.

Moratalla R, Xu M, Tonegawa S, Graybiel AM (1996). Cellular responses to psychomotor stimulant and neuroleptic drugs are abnormal in mice lacking the D1 dopamine receptor. Proc Natl Acad USA 93: 14928-14933.

Morens DM, Grandinetti A, Reed D, White LR, Ross GW (1995). Cigarette smoking and protection from Parkinson's disease: false association or etiologic clue? Neurology 45: 1041-1051.

Moszczynska A, Fitzmaurice P, Ang L, Kalasinsky KS, Schmunk GA, Peretti FJ et al (2004). Why is parkinsonism not a feature of human methamphetamine abusers? Brain 127: 363-370.

Nash JF, Yamamoto BK (1992). Methamphetamine neurotoxicity and striatal glutamate release: comparison to 3,4-methylenedioxymethamphetamine. Brain Res 581: 237-243.

Nishii K, Matsushita N, Sawada H, Sano H, Noda Y, Mamiya T et al (1998). Motor and learning dysfunction during postnatal development in mice defective in dopamine neuronal transmission. J Neurosci Res 54: 450-464.

O’Dell SJ, Weihmuller FB, Marshall JF (1993). Methamphetamineinduced dopamine overflow and injury to striatal dopamine terminals: attenuation by dopamine D1 or D2 antagonists. J Neurochem 60: 1792-1799.

Pahl JJ, Mazziotta JC, Bartzokis G, Cummings J, Altschuler L, Mintz J et al (1995). Positron-emission tomography in tardive dyskinesia. J Neuropsych Clin Neurosci 7: 457-465.

Pereira FC, Imam SZ, Gough B, Newport GD, Ribeiro CF, Slikker Jr $\mathrm{W}$ et al (2002). Acute changes in dopamine release and turnover in rat caudate nucleus following a single dose of methamphetamine. J Neural Transm 109: 1151-1158.

Pfann KD, Penn RD, Shannon KM, Corcos DM (1998). Pallidotomy and bradykinesia: implications for basal ganglia function. Neurology 51: 796-803.

Rascol O, Sabatini U, Brefel C, Fabre N, Rai S, Senard JM et al (1998). Cortical motor overactivation in parkinsonian patients with L-dopa-induced peak-dose dyskinesia. Brain 121: 527-533.

Ricaurte GA, Schuster CR, Seiden LS (1980). Long-term effects of repeated methylamphetamine administration on dopamine and serotonin neurons in the rat brain: a regional study. Brain Res 193: $153-163$.

Ricaurte GA, Schuster CR, Seiden LS (1984). Further evidence that amphetamines produce long-lasting dopamine neurochemical deficits by destroying dopamine nerve fibers. Brain Res 303: 359-364.

Richards JB, Baggott MJ, Sabol KE, Seiden LS (1993). A high-dose methamphetamine regimen results in long-lasting deficits on performance of a reaction-time task. Brain Res 627: 254-260.

Riviere GJ, Byrnes KA, Gentry WB, Owens SM (1999). Spontaneous locomotor activity and pharmacokinetics of intravenous methamphetamine and its metabolite amphetamine in the rat. J Pharmacol Exp Ther 291: 1220-1226. 
Sabol KE, Richards JB, Broom SL, Roack JT, Hausknecht K (2003). Effects of stimulus salience and methamphetamine on choice reaction time in the rat: central tendency versus distribution skew. Behav Pharmacol 14: 489-500.

Sano H, Yasoshima Y, Matsushita N, Kaneko T, Kohno K, Pastan I et al (2003). Conditional ablation of striatal neuronal types containing dopamine D2 receptor disturbs coordination of basal ganglia function. J Neurosci 23: 9078-9088.

Schoffelmeer AN, Hogenboom F, Mulder AH, Ronken E, Stoof JC, Drukarch B (1994). Dopamine displays an identical apparent affinity towards functional dopamine D1 and D2 receptors in rat striatal slices: possible implications for the regulatory role of D2 receptors. Synapse 17: 190-195.

Segal DS, Kuczenski R (1997). Repeated binge exposures to amphetamine and methamphetamine: behavioral and neurochemical characterization. J Pharmacol Exp Ther 282: 561-573.

Segal DS, Kuczenski R, O'Neil ML, Melega WP, Cho AK (2003). Escalating dose methamphetamine pretreatment alters the behavioral and neurochemical profiles associated with exposure to a high dose methamphetamine binge. Neuropsychopharmacology 28: 1730-1740.

Seiden LS, Woolverton WL, Lorens SA, Williams JE, Corwin RL, Hata $\mathrm{N}$ et al (1993). Behavioral consequences of partial monoamine depletion in the CNS after methamphetamine-like drugs: the conflict between pharmacology and toxicology. NIDA Res Monogr 136: 34-46.

Simon SL, Domier C, Carnell J, Brethen P, Rawson R, Ling W. (2000). Cognitive impairment in individuals currently using methamphetamine. Am J Addict 9: 222-231.

Sonsalla PK, Nicklas WW, Heikkila R (1989). Role for excitatory amino acids in methamphetamine-induced nigrostriatal dopaminergic toxicity. Science 243: 398-400.

Sperling LS, Horowitz JL (1994). Methamphetamine-induced choreoathetosis and rhabdomyolysis. Ann Int Med 121: 986.

Szumlinski KK, Balogun MY, Maisonneuve IM, Glick SD (2000). Interactions between iboga agents and methamphetamine sensitization: studies of locomotion and stereotypy in rats. Psychopharmacology 151: 234-241.

Thomas DM, Kuhn DM (2005). Attenuated microglial activation mediated tolerance to the neurotoxic effects of methamphetamine. J Neurochem 92: 790-797.

Thomas DM, Walker PD, Benjamins JA, Geddes TJ, Huhn DM (2004). Methamphetamine neurotoxicity in dopamine nerve endings of the striatum is associated with microglial activation. J Pharmacol Exp Ther 331: 1-17.

Timar J, Gyarmati S, Szabo A, Furst S (2003). Behavioral changes in rats treated with a neurotoxic dose regimen of dextrorotatory amphetamine derivatives. Behav Pharmacol 14: 199-206.
Toomey R, Lyons MJ, Eisen SA, Xian H, Chantarujikapong S, Seidman LJ et al (2003). A twin study of the neuropsychological consequences of stimulant abuse. Arch Gen Psychiatry 60: 303-310.

Toyoshi T, Ukai M, Kameyama T (1996). Opioid receptor agonists selective for mu and kappa receptors attenuate methamphetamine-induced behavioral sensitization in the mouse. Biol Pharm Bull 19: 369-374.

Volkow ND, Chang L, Wang G-J, Fowler JS, Ding Y-S, Sedler M et al (2001a). Low level brain dopamine D2 receptors in methamphetamine abusers: association with metabolism in the orbitofrontal cortex. Am J Psychiatry 158: 2015-2021.

Volkow ND, Chang L, Wang GJ, Fowler JS, Franceschi D, Gatley SJ et al (1999). In vivo evidence that methamphetamine abuse produces long lasting changes in dopamine transporters in human brain. J Nucl Med 40(Suppl): 110P.

Volkow ND, Chang L, Wang G-J, Fowler JS, Franceschi D, Sedler M et al (2001b). Loss of dopamine transporters in methamphetamine abusers recovers with protracted abstinence. J Neurosci 21 : 9414-9418.

Volkow ND, Chang L, Wang G-J, Fowler JS, Franceschi D, Sedler MJ et al (2001c). Higher cortical and lower subcortical metabolism in detoxified methamphetamine abusers. Am J Psychiatr 158: 383-389.

Volkow ND, Chang L, Wang G-J, Fowler JS, Leonido-Yee M, Franceschi D et al (2001d). Association of dopamine transporter reduction with psychomotor impairment in methamphetamine abusers. Am J Psychiatry 158: 377-382.

Wallace TL, Gudelsky GA, Vorhees CV (1999). Methamphetamineinduced neurotoxicity alters locomotor activity, stereotypic behavior, and stimulated dopamine release in the rat. J Neurosci 19: 9141-9148.

Wang G-J, Volkow ND, Chang L, Miller E, Sedler M, Hitzemann R et al (2004). Partial recovery of brain metabolism in methamphetamine abusers after protracted abstinence. Am J Psychiatry 161: 242-248.

Wilson JM, Kalasinsky KS, Levey AI, Bergeron C, Reiber G, Anthony RM et al (1996). Striatal nerve terminal markers in human chronic methamphetamine users. Nat Med 6: 699-703.

Woolverton WL, Ricaurte GA, Forno LS, Seiden LS (1989). Longterm effects of chronic methamphetamine administration in rhesus monkeys. Brain Res 486: 73-78.

Xie T, McCann UD, Kim S, Yuan J, Ricaurte GA (2000). Effect of temperature on dopamine transporter function and intracellular accumulation of methamphetamine: Implications for methamphetamine-induced dopamine neurotoxicity. J Neurosci 20: $7838-7845$ 